\title{
12
}

\section{Ageing, entitlement and funding health care}

\author{
Jane Hall and Kees van Gool
}

Universal access to health-care services funded under Medicare is one of the universal benefit programs targeted for scrutiny as government moves to end, or at least reduce, the age of entitlement. Successive Intergenerational Reports have demonstrated the extent to which health-care expenditure is predicted to grow more rapidly than Commonwealth government spending on aged care and pensions (Commonwealth of Australia 2010; 2015). While the latter is clearly related to population ageing, the former has also been attributed to the same demographic change (for example, Dutton 2014a, 2014b). The predicted growth in health-care expenditure has been characterised as inevitable and as threatening the viability of the health system as it is currently unless some significant changes are made (Ley 2015; Knott 2015). Thus the rhetoric posits causative links from ageing of the population to poorer population health to health-spending blowout to justification for major changes to current health-care financing.

Our intent is to assess these propositions: first, that ageing will inevitably place undue pressure on Medicare; and second, that a system of tax-funded health care is not economically viable. At first glance, it seems paradoxical that improved levels of health (as reflected by decreasing premature mortality) are accompanied by rising outlays on health service use. Therefore, we explore the relationships between 
old age and health status, and health status and expenditure. What we observe is that, although average expenditure increases with age and with number of chronic conditions, the decrease in median health status and the increase in median expenditure is substantially less. There is considerable variability in health levels, particularly at older ages, and in health-care expenditure. As a result, we see a concentration of spending in a relatively small proportion of the population.

We then turn to the need for insurance. Insurance comes about as a way to manage exposure to risk. Individuals face the risk of poor health and potentially high costs for treatment. Although this is uncertain for the individual, it is predictable for population groups when risks are pooled. We explore the role of government in managing risk and argue that the provision of health insurance is a rational response. Medicare is not an unjustified entitlement.

We then turn to recent increases in national health expenditures, to address whether current trends support the view that rising health-care expenditure is out of control. We conclude that ageing per se is not a threat to the sustainability of the Australian health-care system, and that current rates of expenditure are not out of control; so that drastic reductions in access to health care are not justified. Nonetheless the provision of universal insurance introduces other forms of risk and these warrant more investigation to improve health system efficiency.

\section{Expectations of survival and health}

Dramatic falls in mortality have occurred not just in the younger age groups but also in the age group generally regarded as elderly, the over-70s. The result is rising life expectancy. The prevalence of chronic disease is also increasing, with those at older ages more likely to experience multiple chronic conditions and presenting Australia's biggest health challenge (AIHW 2014). To the extent that improved survival means that people are living with diseases that once were fatal, it is likely their health is relatively poor. An increasing prevalence of people in poor health is actually an improvement in overall health once deaths avoided are considered. There have also 
been important changes in what it means to have a chronic disease. Earlier diagnosis is not just possible but encouraged, meaning that even if treatment had not changed people would be living longer with a disease and that is reflected in increasing prevalence of chronic conditions. New US guidelines, for example, have greatly expanded the population for whom initiation of drug therapy for cholesterol is recommended (Stone et al. 2013). If fully implemented in clinical practice, around 13 million more US citizens would be treated with the cholesterol-lowering medications called statins, with most of these patients aged between 65 and 75 (Pencina et al. 2014). But for many diseases, if not most, treatment has changed in a way that has dramatically altered quality of life. In diabetes, for example, new technologies have transformed monitoring and treatment (Polonsky 2012), and patients without complications report quality of life scores only slightly lower than similar aged counterparts (Redekop et al. 2002). Today patients expect to manage their condition, not to have to withdraw from normal life. So it is important not to conflate having a chronic condition with a much poorer health state. It is important to know not just how many conditions people have been diagnosed with, but how they feel.

This can be done by looking at surveys where respondents are asked to rate their own health. We use data reported in 2010 from a large panel household survey in Australia, the Household, Income and Labour Dynamics in Australia (HILDA) survey, of 7,700 Australian households (around 20,000 individuals). This survey uses a standardised measure of health, the SF-6D; respondents are asked to rate their health and functioning against six criteria which cover pain, vitality, physical activities, usual activities such as work, social activities and mental health. The distribution of SF-6D scores by age is shown in Figure 1. More than half the elderly population remains in reasonably good health. These results are consistent with other survey evidence. In the Australian Health Surveys around two-thirds of those over the age of 75 rate their health as good or better (AIHW 2014). 


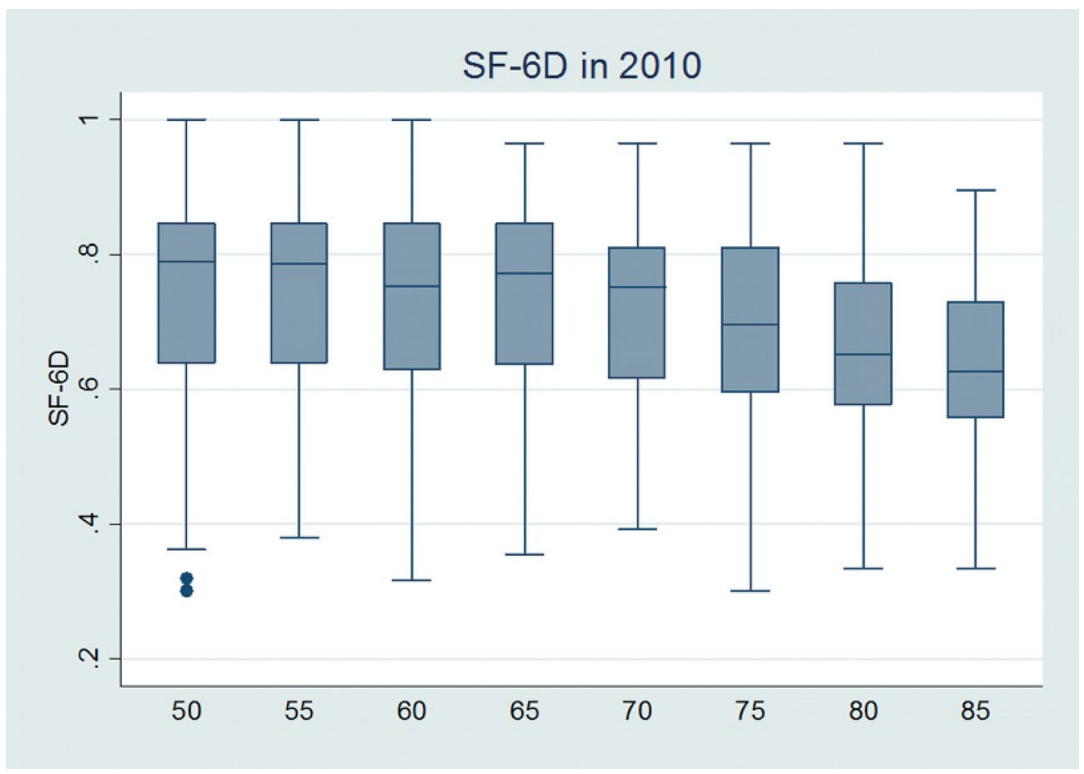

Figure 1. Self-assessed health by age group

Source: van Gool, Mu and Wong's own work based on data provided by HILDA Survey.

\section{Ageing, illness and health-care costs}

Health-care expenditure per person varies over the lifecycle with the lowest average spending in childhood (5-14 year olds) and rising rapidly in the over-50s (AIHW 2014). It is now generally accepted that historical growth has been driven by non-demographic factors, particularly advances in technology. For the future, though, it has been argued that increasing numbers of the older-old, with higher levels of chronic disease, and expectations of new treatments and technologies, will interact to push health-care expenditure to much higher levels. We now turn our attention to the extent to which higher levels of health-care spending are uniform across age groups, and explained by the presence of chronic conditions.

Again we use data from HILDA, in this case the number of selfreported GP visits in 2009. We are interested in moving beyond the mean to consider the median and the range. The median number 
of visits does change with age, as shown in Figure 2, but only slightly. However, we do see greater variability with increasing numbers of high users at older ages.

This can be explored in more detail using another data source, the NSW 45 and Up Study, which surveyed more than 267,000 noninstitutionalised people aged 45 and over and can be linked to multiple health administrative data sets covering all out-of-hospital medical services, all subsidised prescription pharmaceuticals, and hospital use. Total average health expenditure by age demonstrates the expected pattern. Median expenditure increases gradually after the age of 65 , but with a much greater increase in variability for men and women (see Figure 3). The number of chronic conditions explains some but not all of this increase. Median expenditure increases with the number of chronic conditions but the mean increases more rapidly, reflecting high levels of spending in a small group. Interestingly, the same pattern is evident even at older ages, and Figure 4 shows the results for the older age group. Although health cost increases with the number of chronic conditions, there is much greater variation in cost in this sicker group.

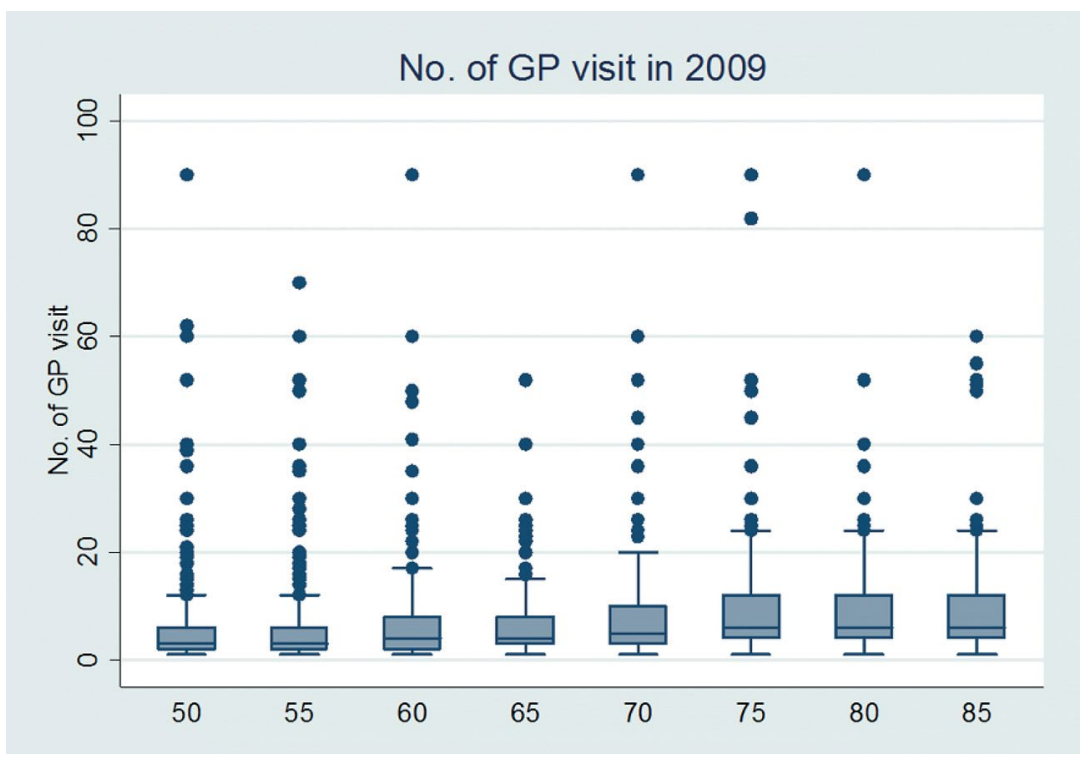

Figure 2. Variation in GP visits by age

Source: van Gool, Mu and Wong's own work based on data provided by HILDA Survey. 


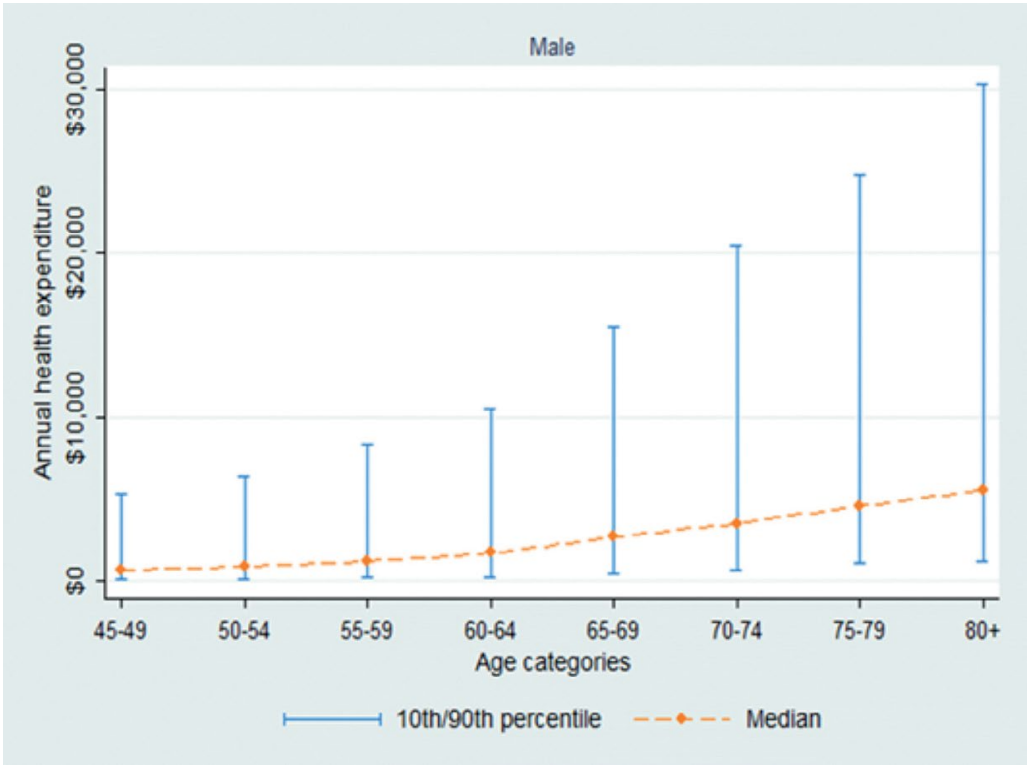

Figure 3A. Health expenditure by age in men 45 and up

Source: van Gool, Mu and Wong's own work based on data provided by the 45 and Up Survey linked to MBS and PBS and hospital, NSW Australia (2010).

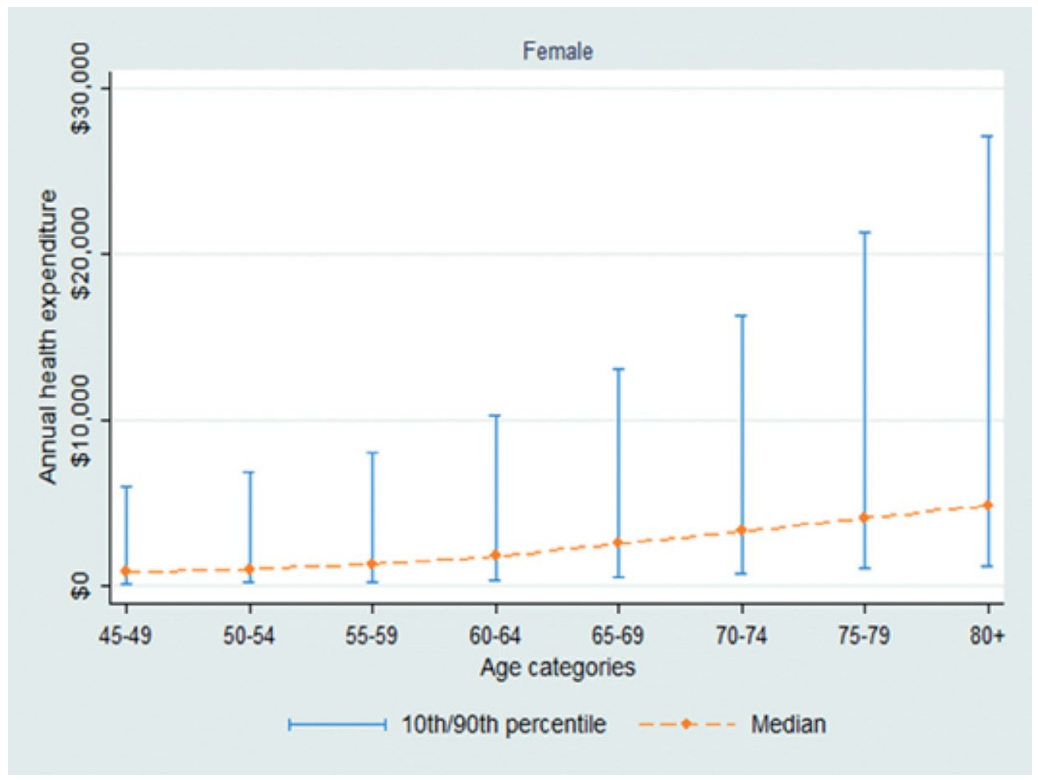

Figure 3B. Health expenditure by age in women 45 and up

Source: van Gool, Mu and Wong's own work based on data provided by the 45 and Up Survey linked to MBS and PBS and hospital, NSW Australia (2010). 


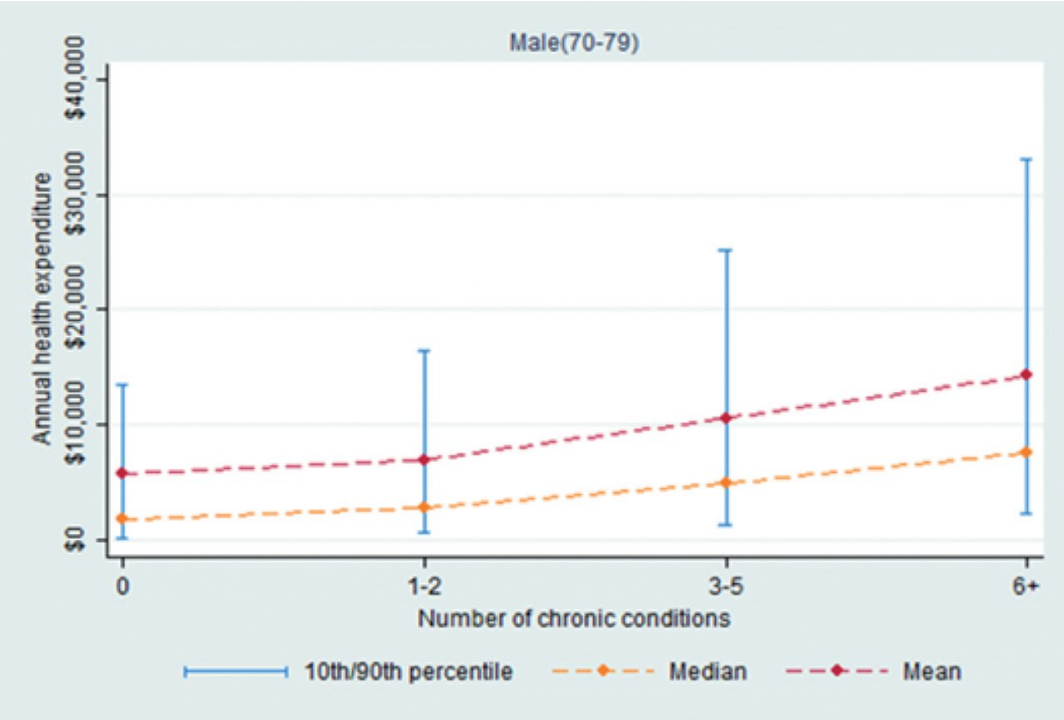

Figure 4A. Health expenditure in men 70-79 years by number of conditions

Source: van Gool, Mu and Wong's own work based on data provided by the 45 and Up Survey linked to MBS and PBS and hospital, NSW Australia (2010).

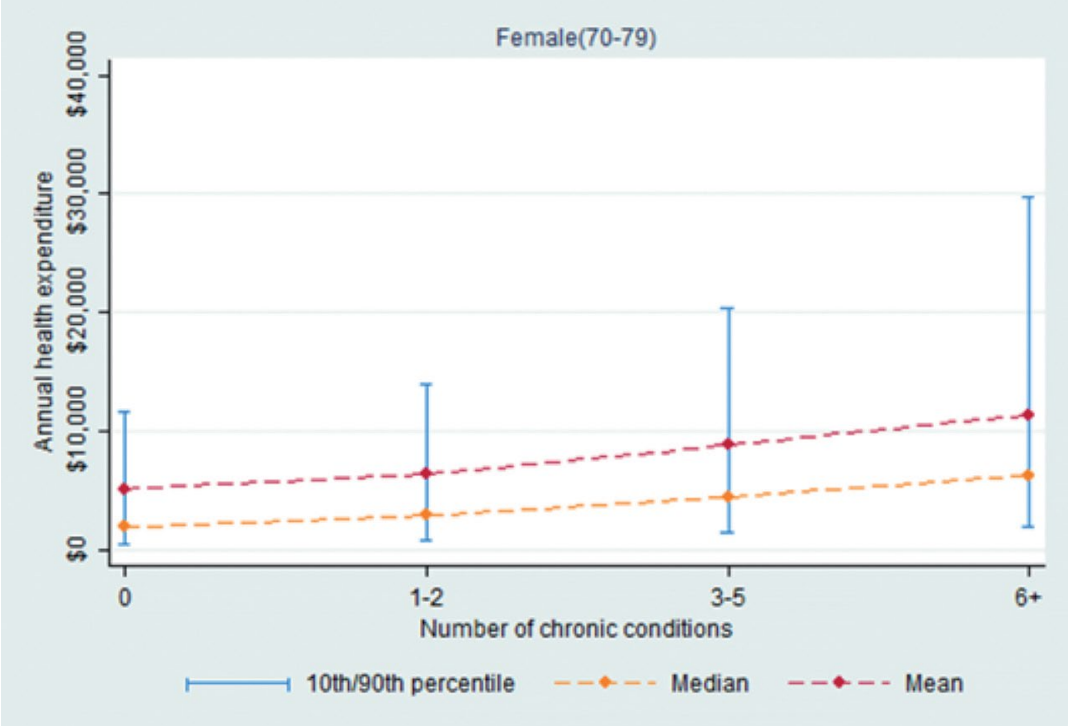

Figure 4B. Health expenditure in women $70-79$ years by number of conditions

Source: van Gool, Mu and Wong's own work based on data provided by the 45 and Up Survey linked to MBS and PBS and hospital, NSW Australia (2010). 
However, the increasing number of chronic conditions is a measure of multi-morbidity but not necessarily the seriousness of the conditions or the frailty of the patient. Our observation of increased variability with multi-morbidity may reflect that we have not captured severity adequately. Time to death has also been shown to be associated with higher levels of expenditure (Hoover et al. 2002; Moorin and Holman 2008), with a marked increase in the year before death. The linkage of 45 and Up with death registrations allows us to investigate this. Similarly, the increase in spending in the 12 months prior to death is marked (Figure 5). Again, the mean level of expenditure increases more than the median, with much greater variability in spending in the year before death. Further, we find that the largest share of costs is hospital inpatient care, a finding that replicates others (Kardamanidis et al. 2007).

To some extent, this is simply explained: hospitals are expensive places. Over half of Australian deaths occur in hospitals, even at older ages (Broad et al. 2013). Death at younger ages is less expected and less accepted, and so intensive (and expensive) treatment is justified. But this is not the case for older people, most of whom would prefer to die at home (Gomes et al. 2013). A survey of US physicians asked which of various potentially intensive treatments they would want for themselves if they were considered towards the end of their lives (Gallo et al. 2003). Such therapies included chemotherapy, artificial feeding, ventilation, dialysis and invasive testing. Over 80 per cent would definitely want pain relief; but most would not want other frequently used interventions. It is important to ask whether healthcare spending is being driven by expensive and invasive therapies that the recipients actively do not want. 


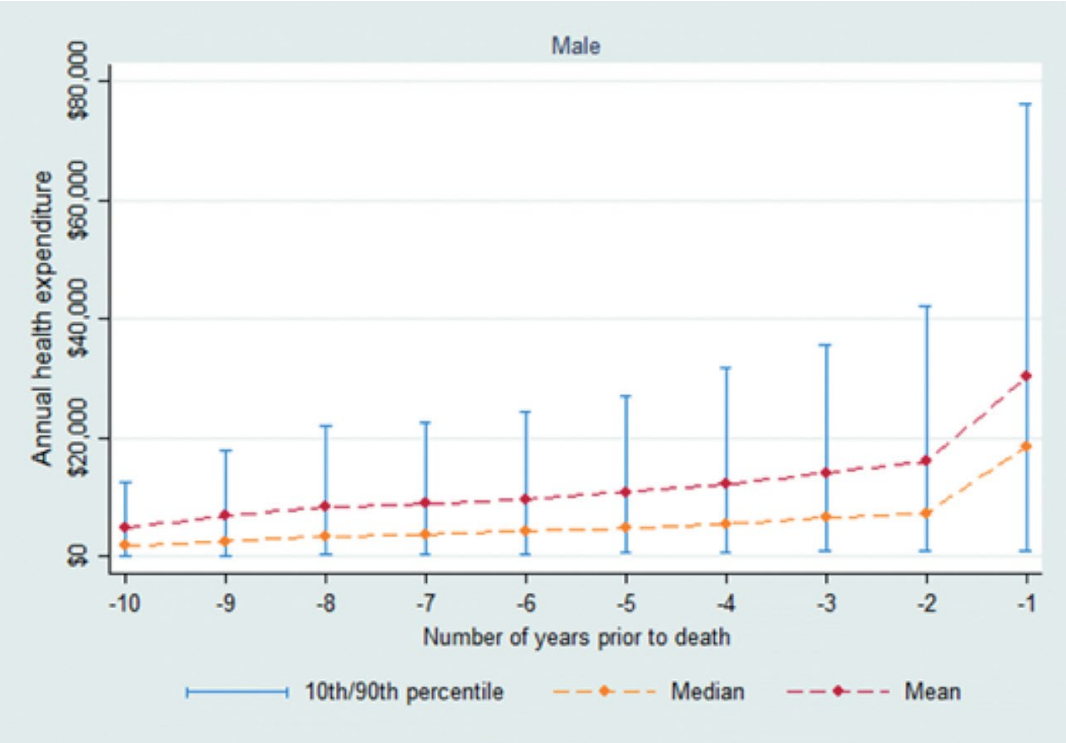

Figure 5A. Expenditure by time to death

Source: van Gool, Mu and Wong's own work based on data provided by the 45 and Up Survey linked to MBS and PBS and hospital, NSW Australia (2010).

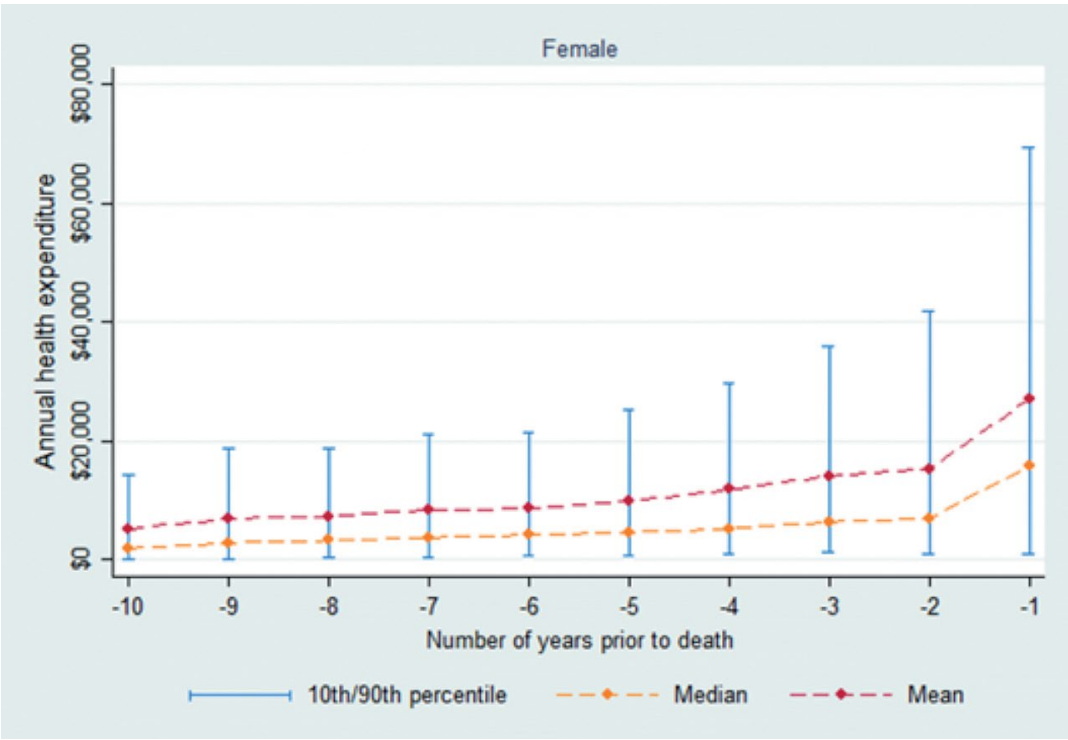

Figure 5B. Expenditure by time to death

Source: van Gool, Mu and Wong's own work based on data provided by the 45 and Up Survey linked to MBS and PBS and hospital, NSW Australia (2010). 


\section{The concentration of health-care spending}

Australian data show wide variation in health status at every age, and at older ages. Many older people are in good health or better. And a growing number with poorer health could well be a consequence of what was once acute, life-ending illness being transformed into a chronic condition. Improvements in medical technology have allowed for earlier detection of conditions (e.g. diabetes) with the benefits of earlier intervention and better management. This has also created new medical conditions (high cholesterol) and new opportunities for commercialisation; after all, a medical condition is generally something for which there is a viable treatment. As a result, it is not valid to compare 'chronic conditions' measured today with those observed a generation ago. The growing prevalence of chronic conditions does not mean people feel worse. Although there is an increase in healthcare expenditure with age and with increasing conditions, what is more striking is that there is such an increase in variability with the number of conditions, and with proximity to death.

The concentration in health-care spending is well summarised by the concentration curves in Figure 6, again using the NSW 45 and Up data. These rank individuals by health-care spending and show how the share of total expenditure corresponds to the proportion of the population. This pattern of high levels of expenditure concentrated in a fairly small proportion of the population has been well established with US data (Cutler and Zeckhauser 2000); but to our knowledge this has not been demonstrated with Australian data. It is not surprising that there is a high degree of concentration with 25 per cent of the population accounting for 80 per cent of total expenditure. Remember this is for an older group, NSW residents aged 45 and over. We would expect an even stronger concentration for all ages. Perhaps more surprisingly, when this is analysed by age group, as shown in Figure 6, the pattern remains, even for the older groups. 


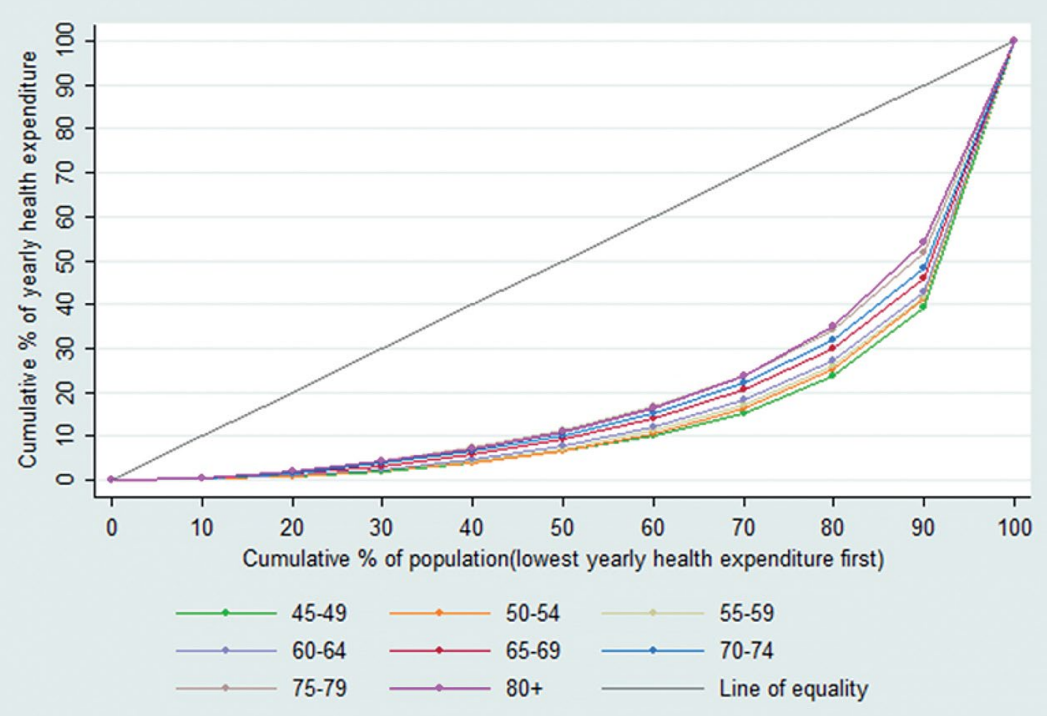

Figure 6. Concentration curves for health care expenditure by age

Source: van Gool, Mu and Wong's own work based on data provided by the 45 and Up Survey linked to MBS and PBS and hospital, NSW Australia (2010).

At this point, it seems clear that ageing is not the problem. We see that many Australians live into old age with good health, and even for those with multiple chronic conditions, many remain low spenders. The challenge is to understand why some people are healthy and why some are big spenders. There are potentially a number of underlying reasons, each of which suggest a different response: unpredictability at the individual level; poor management and high prices; missed opportunities for prevention. The unpredictability of illness for any individual and the potentially high (catastrophic) financial losses provides the case for insurance; better to exchange a certain small loss (the cost of insurance) rather than face the uncertain prospect of very expensive treatment, or no treatment because it is beyond one's means. As we have already shown, the concentration of health-care spending remains after accounting for age and chronic conditions, which suggests that these two factors do not explain much of the observed variation. The observation of higher expenditures and hospital use in the months before death is consistent with a greater severity explanation. There are other uncertainties in addition to severity. Some illnesses are simply more expensive to treat while some individuals do not respond well to one treatment and may require alternative interventions or treatment for complications. 


\section{The challenge for health care insurance}

A system of health-care financing is needed to prevent people not getting health care when they cannot afford it; and to ensure that people do not face unreasonable financial hardship when sick and needing care. This type of risk is generally addressed by some form of insurance, which allows for the pooling of financial risk. However, insurance brings with it moral hazard; if the results of loss are ameliorated, then individuals may take less care to avoid the loss.

The whole concept of moral hazard needs to be considered carefully in the context of health. Health insurance actually provides protection against the cost of health service use. It cannot guarantee to restore lost health, and even where treatments are completely effective they frequently involve time, pain, discomfort and loss of dignity. So it is unlikely that individuals will intentionally risk their health for the fun of consuming health care. Moral hazard does enter the picture, though. Insurance typically includes some services and excludes others, so providers, simply by selecting what services they fund, will encourage consumers to use those services in preference to others. Historically, this has favoured treatment for an identified disease/ condition and excluded prevention; and Medicare favours services provided by a medial practitioner where the patient is present over allied health providers, or telephone or email consultations. Now it would seem sensible for an insurer to invest in prevention to avoid expensive payouts for treatment; but the time required to reap the returns on prevention is often many years.

Once individuals become patients they rely on medical providers' advice as to what type of health-care consumption they require and who is best placed to provide that. The combination of moral hazard and asymmetry of information results in higher expenditure, as the patient/doctor decision tends towards higher use of services and to be less price sensitive than if they faced the full costs. This is not necessarily over-use in any normative sense; after all the point of insurance is to reduce the costs faced at the point of service so as to encourage people to consume health care. But there is a challenge in distinguishing needed (or more valuable) from unnecessary (or less valuable) care. There is also the opportunity for providers to charge higher prices than they would without insurance. 
So however insurance is organised, there is a need to address the various issues raised by moral hazard and information asymmetries. Some strategies involve passing some risk back to the customer, for example co-payments, front-end deductibles, a limit to the amount that the insurer will pay. Others involve passing the risk on to providers, such as through capitation arrangements or encouraging use of government-financed services. Yet another approach is favourable risk selection, that is to encourage good risks and discourage bad risks from buying insurance. Risk is pervasive and the challenge for health financing is how to manage and share it, while still meeting the goal of universal access but not introducing perverse incentives.

\section{The role of government}

Government has an essential role to play in regulating markets. This applies no less in health care, where government involvement in health-care markets is a prerequisite for efficient market functioning. Indeed, without government's power to ensure some redistribution, many groups would be priced out of the health-care market. Given that many chronic conditions are associated with low socioeconomic status and age, an important aspect of universal coverage is that it raises the health care purchasing power of the poor and sick, which then affects the type and distribution of health care supplied. Universal coverage is not just vital for financial protection from high healthcare costs for these groups but is likely to generate better population health outcomes.

Even without the need for redistribution, government will intervene to regulate competition. The market for health insurance is beset with widespread failure, including risk selection, the potential for individuals to under-insure, and protecting the insured from an insurance firm going out of business. A broader way to see this, rather than just regulation of a market, is as regulation and management of risk. As Moss (2002) explains and chronicles in his book, government, even in the US, plays a major and pervasive role in managing risks through various approaches but is the ultimate risk manager. Once that view is adopted, we can see that there are different ways to meet the insurance function with differing degrees of government involvement. At one extreme is a market of competitive private insurance funds. Even in such a private market, regulation will be required to manage risk, 
particularly under-insurance and the failure of a particular firm. Government will be required to cover poor risk groups, either directly, such as in the US with Medicare and Medicaid, or though regulation of premiums (such as community rating) or subsidy. The other extreme is a national health service where government is not just the insurer, but the provider of care, for example, owning and operating hospitals and contracting with doctors such as the British National Health Service. In between, government may provide the insurance function financed through general taxation, as is the case in Australia. Whichever approach is chosen, there will be government involvement as the ultimate risk manager.

There are benefits to government as insurer. Universal cover can be assured through the government's power to collect payments. The government can directly address the need for redistribution and provide the disadvantaged, low-income groups and those with multiple diseases with insurance cover. Government can save on the costs of monitoring market functioning, in addition to the savings from the overheads and administrative costs of multiple insurers. Government will benefit from the long-term investment in prevention. In our view, government tax-based insurance is not an entitlement but a rational option for addressing society's need for health insurance.

\section{Can Australia afford to spend more on health care?}

Health-care expenditure has increased at a faster rate than national income; this phenomenon has been observed over time and across countries (OECD 2013). The real growth in health-care expenditure for Australia has averaged 5.1 per cent pa over the decade to 2012-13 (AIHW 2014). Even though ageing is not 'the problem', it is reasonable to ask whether this can be maintained in the future. Financial sustainability can be considered from the perspective of the economy and whether future economic growth can continue to support a growing share. Compared to other OECD countries, Australia still is very average in the proportion of GDP spent on health care; countries that spend more include New Zealand and Canada. The most recent health-care expenditure data for Australia has shown some slowdown in growth. While one data point does not establish a trend, international evidence 
shows a similar slowing of growth in other developed countries. Across the OECD, many countries hit by the global financial crisis (GFC) in 2009 have achieved a significant reduction in the growth in health spending. This is not surprising given the dimensions of the GFC and, in many countries, the imposition of strict austerity. What is interesting, and perhaps less expected, is that across 16 OECD countries, the economic recessions of the 1970s, the 1980s, and 2000s were followed by a downturn in health-expenditure growth, and that lower rate of growth has been sustained even during the following economic booms.

And for the future, even conservative predictions of economic growth will easily cover the expected increases in expenditure (Richardson 2014). Thus it is difficult to argue that health expenditure is out of control. The perspective of the economy as a whole is a more important question than the limited perspective of the Australian Government taken in the successive Intergenerational Reports. Successful constraint of federal government outlays may simply shift cost to other payers in the system; reducing the funding of public hospitals shifts the burden to states and territories, while consumer co-payments shifts financing to patients.

That conclusion does not rule out the question of whether the health system can be made more efficient. We have already pointed to the potential for moral hazard and its effects on health-care spending. We have demonstrated that there is substantial variation in spending patterns. More research is required to disentangle warranted and unwarranted variation and expenditure. Opportunities for improving the performance and efficiency of health services can meet any challenges of rising expenditures; and, as the Productivity Commission pointed out, is a superior way of meeting the challenges ahead (Productivity Commission 2013).

\section{Conclusion}

The ageing of the Australian population is not a threat to the continued viability of the Australian health-care system. Many older people remain in good health, and place modest demands on the health services. The high concentration of health-care expenditure at all ages, with a relatively small group of the population accounting for 
the bulk of expenditure, points to the need for insurance. Insurance can be provided in different ways with tax-financed universal health-care insurance as one option. Medicare with its universality is a reasonable social choice. Indeed, universal coverage and high levels of public insurance must be part of the solution to the healthy ageing policy challenge. The new analyses presented here demonstrate that there is widespread variation in health service use and expenditure, which is not explained by age or health status. More research is needed to disentangle warranted variation that should be addressed by insurance, and unwarranted variation that should be addressed by improving incentives. Meanwhile, policy reforms that are aimed at the average are likely to miss their target and have sub-optimal health and financial consequences.

\section{References}

Australian Institute of Health and Welfare (AIHW) (2014). Australia's health 2014. Australia's health series no. 14, Cat. no. AUS 178. Canberra: AIHW.

Broad Joanna, Gott Merryn, Kim Hongsoo, Boyd Michael, Chen He and Connolly Martin J (2013). Where do people die? An international comparison of the percentage of deaths occurring in hospital and residential aged care settings, using published and available statistics. International Journal of Public Health, 58(2): 257-267.

Commonwealth of Australia (2010). Australia to 2050: Future challenges. The 2010 Intergenerational Report. Canberra: Department of Treasury. archive.treasury.gov.au/igr/igr2010/report/pdf/IGR_ 2010.pdf. Accessed April 2013.

Commonwealth of Australia (2015). 2015 Intergenerational Report: Australia in 2055. Canberra: Department of Treasury. March 2015.

Cutler David and Zeckhauser Richard (2000). The anatomy of health insurance. In AJ Culyer and JP Newhouse (Ed) Handbook of Health Economics. Elsevier. 
Dutton Peter (2014a). Address to Australian Private Hospitals Association, 33rd National Congress, Brisbane, 24 March 2014. www.health.gov.au/internet/ministers/publishing.nsf/Content/6 7B35AD121 B08BABCA257CA500700E7D/\$File/PDSP130324.pdf. Downloaded September 2014.

Dutton Peter (2014b). Rising Cost of Good Health. Press Release. 24 June 2014. www.health.gov.au/internet/ministers/publishing.nsf/ Content/97704DD4D6734CB8CA257D0200076F22/\$File/PD044.pdf. Downloaded September 2014.

Ellis Randall, Fiebig Denzil, Johar Meliyanni, Jones Glenn and Savage Elizabeth (2013). Explaining Health Care Expenditure Variation: Large-Sample Evidence Using Linked Survey And Health Administrative Data. Health Economics, 22(9): 1093-1110.

Gallo Joseph, Straton Joseph, Klag Michael, Meoni Lucy, Sulmasy Daniel, Wang Nae Yuh and Ford DE (2003). Life-sustaining treatments: What do physicians want and do they express their wishes to others? Journal of the American Geriatrics Society, 51(7): 961-969.

Garner Jessica (2014). GP trial wins more loyalty. Australian Financial Review. 17 October 2014.

Gomes Barbara, Calanzani Natalie, Gysels Marjolein, Hall Sue and Higginson Irene J (2013). Heterogeneity and changes in preferences for dying at home: A systematic review. BMC Palliative Care 12: 7. doi: $10.1186 / 1472-684 x-12-7$.

Gosden Toby, Forland Frode, Kristiansen Ivar, Sutton M, Leese B, Giuffrida A, Sergison M and Pedersen L (2011). Capitation, salary, fee-for-service and mixed systems of payment: Effects on the behaviour of primary care physicians. The Cochrane Database of Systematic Reviews, (3): CD002215.

Hoover Donald, Crystal Stephen, Kumar Rizie, Sambamoorthi Usha and Cantor Joel C (2002). Medical Expenditures during the Last Year of Life: Findings from the 1992-1996 Medicare Current Beneficiary Survey. Health Serv Res. 37(6): 1625-1642. 
Kardamanidis Katina, Lim Kim, Da Cunha Cristalyn, Taylor Lee K and Jorm Louisa R (2007). Hospital costs of older people in New South Wales in the last year of life. Medical Journal of Australia, 187(7): 383-386.

Knott Matthew (2015) Joe Hockey raises the prospect of Australians living until 150 to justify budget cuts. Sydney Morning Herald, 19 January. www.smh.com.au/federal-politics/political-news/joehockey-raises-prospect-of-australians-living-until-150-to-justifybudget-cuts-20150119-12t3ml.html.

Ley Sussan (2015). Government to consult on Medicare reform. Media Release. sussanley.com/government-to-consult-on-medicare -reform/. Accessed 23 January 2015.

Moorin Rachael and Holman D'Arcy (2008). The cost of in-patient care in Western Australia in the last years of life: A population-based data linkage study. Health Policy, 85: 380-390.

Moss David (2002). When All Else Fails: Government as the ultimate Risk Manager. Cambridge MA: Harvard University Press.

Organisation of Economic Co-operation and Development (OECD) (2013). Health at a Glance 2013: OECD Indicators. Paris: OECD Publishing.

Pencina Michael, Navar-Boggan Ann Marie, D'Agostino Ralph, et al. (2014). Application of new cholesterol guidelines to a populationbased sample. New England Journal of Medicine, 370: 1422-1431. doi: 10.1056/NEJMoa13156.

Polonsky Kenneth (2012). The Past 200 Years in Diabetes. New England Journal of Medicine, 367: 1332-40. doi: 10.1056/NEJMral 110560.

Productivity Commission (2013). An Ageing Australia: Preparing for the Future, Productivity Commission Research Paper, Canberra: Productivity Commission.

Redekop Ken, Koopmanschap Marc, Stolk Ronald, Rutten Guy, Wolffenbuttel Bruce and Niessen Louis (2002). Health-Related Quality of Life and Treatment Satisfaction in Dutch Patients with Type 2 Diabetes. Diabetes Care, 25(3): 458-463. doi: 10.2337/ diacare.25.3.458. 
Richardson Jeffrey (2014). Can we sustain health spending? Medical Journal of Australia, 200(11): 629-631.

Sax Institute 45 and Up Survey: www.saxinstitute.org.au/ou-work/45up-study (accessed 23 January 2015).

Stone Neil, Robinson Jennifer, Lichtenstein Alice, et al. (2013). ACC/ AHA guideline on the treatment of blood cholesterol to reduce atherosclerotic cardiovascular risk in adults: A report of the American College of Cardiology/American Heart Association Task Force on Practice Guidelines. Journal of the American College of Cardiology, 63(25).

Wooden Mark and Nicole Watson (2007). The HILDA Survey and its Contribution to Economic and Social Research (So Far), The Economic Record, vol 83, no. 261, pp. 208-231. 
This text is taken from Population Ageing and Australia's Future, edited by Hal Kendig, Peter McDonald and John Piggott, published 2016 by ANU Press, The Australian National University, Canberra, Australia. 